\title{
$\mathrm{s}^{2}$ \\ Anthropology \& Aging \\ Journal of the Association for Anthropology \& Gerontology
}

\section{"Cinderella Men": Husband- and Son- Caregivers for Elders with Dementia in Shanghai}

\author{
Yan Zhang \\ Harvard Medical School, Harvard University \\ yan_zhang@hms.harvard.edu
}

\begin{abstract}
Traditionally, women had the day-to-day responsibility for eldercare. However, social changes have created alternatives for men to take on what is generally considered a "female duty." Particularly, as the prevalence of dementia has increased in China, men are increasingly becoming the primary caregivers for their kin. Yet, we have limited understanding of male caregiving. Based on a twentymonth ethnographic study of 60 men taking care of a relative with dementia, this paper examines motivations, practices, struggles and strategies of male caregivers. While acknowledging the gendered nature of caregiving, I argue that eldercare goes beyond solely social construction of gender roles and power asymmetries between males and females. Men-both husbands and sonswho engage in caregiving are motivated by love, affection, moral obligation, reciprocity based on past assistance, and property inheritance. Male caregivers' care practices and their responses toward challenges vary from case to case, yet these differences have less association with gender identity but more with cohort variations. The expanding home roles of male caregivers call attention to the social transformation of gendered care practices in China and beyond.
\end{abstract}

Keywords: gender roles; men; caregiving; dementia; China

Anthropology \& Aging, Vol 42, No 2 (2021), pp. 6-20

ISSN 2374-2267 (online) DOI 10.5195/aa.2021.356

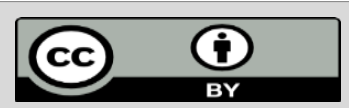

This work is licensed under a Creative Commons Attribution 4.0 International License.

This journal is published by the University Library System of the University of Pittsburgh as part of its

D-Scribe Digital Publishing Program, and is cosponsored by the University of Pittsburgh Press. 


\title{
"Cinderella Men": Husband- and Son- Caregivers for Elders with Dementia in Shanghai
}

\author{
Yan Zhang \\ Harvard Medical School, Harvard University \\ yan_zhang@hms.harvard.edu
}

\section{Introduction}

Social scientists have documented major changes in gender roles and relationships in China since the Mao era. Changes in institutions and cultures have played a significant role in facilitating gender equality for education and employment. During the Maoist period, the ideology of gender equality was prioritized by the state and women were equally appointed to job positions in both rural and urban China (Jin 2006; Li 2000; Tsai 1996). Currently, additional policies are being issued to ensure women's education and labor rights, which are significantly improving women's social status (Tao et al. 2004; Xie 2013). Within domestic settings, compared to the traditional patriarchal family structure, some sociological studies argue that women have gained more decision-making power regarding their marriage, birth-control, property inheritance, and labor division (Davis 2010; Shi 2017; Zhang and Fussell 2017). However, another school of sociologists agree with Hochschild and Machung's (1989) portrayal of employed women as suffering from a double burden: women are simultaneously involved in socioeconomic activities and household labor (such as childcare and eldercare).

Only studying women ignores the complex interrelationships that form the gender system of a society. Increasingly, scholars are recognizing the changes in men's lives that are concomitant with changes in women's lives (Zhang and Fussell 2017). As one of the first five cities to open to foreign trade over 150 years ago, Shanghai is the most Westernized city in mainland China. Women there arguably have the highest status in China in terms of gender equality, at least in the private sphere. It is the norm for women to manage the family finances in Shanghai (Da 2004; Long 1999; Xu and Yeung 2013). Men that engage in domestic care practices such as taking care of ill family members are frequently reported by newspapers and popular magazines (Bells 2011; Chen 2012; China Daily 2006). The media refers to this group of men as nuannan or "Cinderella men." In addition to the percentage increase of employed women, spousal and son caregivers constituted $27.3 \%$ and $22.8 \%$ respectively of caregivers for the elders in Shanghai (Yin and Zhou 2014). As developed countries have experienced, socioeconomic and demographic trends have led to increasing numbers of men taking on what is generally considered "women's work" (Harris and Long 1999; Long and Harris 2000; Miller and Kaufman 1996). Yet, this strategic gender performance has been overlooked in previous studies of gender structures in China.

This paper contributes to our understanding of the changes in the gender system in China by examining male caregivers' motivations, practices, struggles and strategies during dementia caregiving. I argue that eldercare goes beyond solely social construction of gender roles and power asymmetries between males and females. Men - both husbands and sons - who engage in caregiving are motivated by love, affection, moral obligation, reciprocity based on past assistance, and property inheritance. Male caregivers' care practices and their responses toward challenges vary from case to case, yet these differences have less association with gender identity but more with cohort variations. 


\section{Caregiving as a Gendered Experience}

Caregiving is structured along gender roles and the process of socialization produces both prescribed and proscribed behaviors. For example, women engaged in care tasks are performing within gender expectations whereas men are supposed to be career oriented. Such "appropriate" and "inappropriate" behavioral differentiation may encourage women to adhere nurturing activity and prevent men from engaging in care tasks (Montgomery 1992). This gendered approach to family caregiving for elders with dementia has demonstrated statistical differences between males and females. According to the Bureau of Labor Statistics in the US (2019), 58\% of unpaid labor were women in 2018. Similar results can be found in developing countries. According to the World Alzheimer's Report (ADI 2009), most patients with dementia are cared for at home with women composing $70-80 \%$ of the primary caregivers. These statistics reinforce the notion that gender roles powerfully influence care arrangements globally. While men are becoming involved in caregiving processes, appropriate gender roles further divide care tasks. Most personal and hands-on care is provided by women, whereas men are more likely to engage in tasks that require physical labor - such as home repair and maintenance, intermittent assistance, or care arrangement (Gerstel and Gallagher 2001; Russell 2007; Sharma et al. 2016). Moreover, the social construction of gender roles is further complicated by cultural factors; in Japan, even though demographic changes have caused men to participate in caregiving, women are still considered "professional housewives" (Vogel 1978) and the main caregivers for seniors (Long and Harris 2000; Traphagan 2003).

This gendered division of labor has led to different experiences of caregiving. For instance, in terms of caregiving burden and workload, some research findings suggest man caregivers tend to have less burden and depression than woman caregivers (Friedemann and Buckwalter 2014; Yee and Schulz 2000). This is probably due to the assumption that caregiving is a female duty. Swinkels and colleagues (2019) also found that secondary stressors related to caregiving (such as relational/financial issues and problems combining different tasks) can lead to wife caregivers experiencing greater challenges than husband caregivers. Consequently, female caregivers tend to report lower levels of physical health and more psychiatric morbidity than male caregivers (Yee and Schulz 2000). In terms of coping strategies, some studies show that men are more likely to be isolated and not utilize social services and support (Black et al. 2008; Neufeld and Kushner 2009; Russell 2001).

While acknowledging that the social construction approach helps us understand the gendered care practice, power asymmetry between genders and its relationship to caregiving are better illustrated by the feminist approach. Feminist scholars argue that care should be viewed as a political concept because the unrecognized work of women in caring for the sick and disabled at home contains public costs (Engster 2015; Robinson 2011; Tronto 1993). These scholars advocate the link of gender and politics by offering a framework for understanding power relations between genders. For example, Calasanti (1999) defines gender relations as "socially constructed power relations between women and men, which become institutionalized in various social arenas" (45). These power relations privilege men by disadvantaging women and intertwine with class, ethnicity, race, and nationality. These power asymmetries within family and societies have affected the assignment of care tasks and will reinforce inequalities between genders.

Indeed, feminisms' advocates have contributed to the change in the care landscape since the early 1990s, with more men now participating in caregiving. Yet, we do not know how men are practically engaged in caregiving and interpret their new home roles. Thus, an examination of male caregiving and the 
surrounding social context is urgently needed. In societies with rapid social changes, the agenda that women are naturally caregivers for their husbands or parents will not be sustainable owing to the demographic shifts, changing gender roles, and eroding traditional family values in developing countries (Jesmin et al. 2011). For example, in China, challenges of family-based eldercare may be exacerbated by the one-child policy, rapid modernization, and eroding family values, resulting in fewer adult children available for providing such care. Men, especially husbands, will become an important source of caregiving. Yet, we do not know what motivate men to take on caregiving and whether gender identity affects their care practices. If so, are there any individual and cohort variations within the group of male caregivers, e.g., between husband- and son- caregivers in the extent of hands-on care, attitudes toward caregiving, and relations with other family members? Therefore, the examination of men's caregiving experiences will shed light on the dynamics of cultural values, family structure, and social change in China and beyond.

\section{Methods}

This paper is part of a larger research project focusing on family caregiving for elders with dementia in Shanghai. As the largest city in China, Shanghai had more than 14 million residential citizens, of which $34.4 \%$ were older adults aged 60 and above in 2018 (SRCA 2019). Family-based eldercare is the primary source for elders who are chronically ill and need long-term support.

I conducted in-depth interviews with 144 family caregivers, of which 60 were males, in Shanghai from 2014 to 2017. The narratives and experiences exemplified below were primarily collected in 2017 . These male caregivers include 20 sons and 40 husbands. Ranging from age 28 to 90 years, the majority were in their $60 \mathrm{~s}$ and $70 \mathrm{~s}$. The age cohorts can be found in Table 1. Among the 20 son caregivers, 16 were caregiving for their mothers and 4 for their fathers. Among the 60 research subjects, 16 (6 sons and 10 husbands) were randomly chosen from a community-based dementia care program. They were residents and lived in $\mathrm{W}$ community where I did my fieldwork. The remaining 44 male caregivers (14 sons and 30 husbands) were randomly chosen from the list of regular visitors in a memory clinic near W community.

Due to the comprehensive pension and healthcare insurance systems in Shanghai, there were no distinct differences in terms of economic circumstances between caregivers from the community and those from the memory clinic. Most family caregivers were born in or before the 1960s. The education levels of family caregivers were generally flat as a result of the Cultural Revolution and other social movements during the Mao era; therefore, education cannot be a reliable factor to distinguish one subject from the other. Since most family caregivers have retired, I'm examining their monthly pension or income as a primary indicator of economic circumstances.

Based on the monthly pension or income, majority of these male caregivers were middle class $(n=57)$ and the remaining relatively poor $(n=3)$. The exact pension varies from case to case due to the years of work history and types of employment. The highest pension reported from one husband caregiver and his wife was approximately 15,000-20,000 RMB [\$2,100-2,800 USD] because they participated in the Civil War and contributed to the liberation of the country. Majority of family caregivers and care recipients had their monthly pension ranging from 3000 to 7000 RMB [\$420-980 USD]. While most caregivers had retired, there were 6 son caregivers and 1 husband caregiver at the working age (below 55): 4 had work duties, 1 (age 53) requested an early retirement, 1 (age 52) was temporarily unemployed, and 1 (age 52) completely relied upon unemployment subsidies from the government. Among the 60 care recipients, $2 \mathrm{had}$ no pension due to their advanced age and lack of formal work experience. These two care recipients relied on government subsidies valuing 790 RMB [\$110.6 USD] per month in 2017. 
Table 1 Characteristics of Male Caregivers $(\mathrm{N}=60)$

\begin{tabular}{|c|c|c|}
\hline Characteristics & $\begin{array}{l}\text { Sons } \\
(n=20)\end{array}$ & $\begin{array}{l}\text { Husbands } \\
(n=40)\end{array}$ \\
\hline \multicolumn{3}{|l|}{ Age } \\
\hline$=<50$ & 2 & 0 \\
\hline $51-55$ & 4 & 1 \\
\hline $56-60$ & 6 & 0 \\
\hline $61-65$ & 5 & 2 \\
\hline $66-70$ & 2 & 7 \\
\hline $71-75$ & 0 & 9 \\
\hline $76-80$ & 1 & 8 \\
\hline $81-85$ & 0 & 9 \\
\hline 86-90 & 0 & 4 \\
\hline Median age & 60 & 76 \\
\hline \multicolumn{3}{|l|}{ Care arrangement } \\
\hline Solo Caregiving & 17 & 28 \\
\hline With home-aide support & 3 & 3 \\
\hline With siblings' support & 0 & - \\
\hline With adult-child support & - & 9 \\
\hline \multicolumn{3}{|c|}{ Potential female family supporters } \\
\hline With the only child & 0 & 12 \\
\hline With at least one sister & 17 & - \\
\hline With at least one daughter & - & 29 \\
\hline
\end{tabular}

Care arrangements are affected by both economic circumstances and the availability of female family supporters. While most son caregivers had sisters, they ended up with solo caregiving for various reasons (as I discuss below). The stories of husband caregivers seemed to be affected by the one-child policy since 12 husband caregivers had only one child. The previous mutual support between generations seemed to continue to decline since only 9 husband caregivers received some support from their adult children. When husband caregivers had daughters, they seemed to withdraw from the traditional caregiving responsibility. The availability of pensions could enable male caregivers to shop on the market for social services, yet only 3 sons and 3 husbands hired home aides for help. Most care tasks were still these male caregivers' responsibility.

Indeed, these statistics can give us a basic glance of male caregiving in terms of who, how many, or how often interviewees touched on a given issue. However, this study does not aim to quantify their stories. Instead, my goal is to understand the social context of male caregiving and the differences between husband- and son- caregivers in terms of their experiences and to conceptualize, theorize, and explain their motivations, practices, struggles and strategies. For interview transcripts quoted here, I provide only the English translations. To preserve confidentiality, I did not give full names for my informants.

\section{Motivations}

The rationales associated with care arrangement in domestic settings are related to the question, "Who does the care work and why?" Husband caregivers often attribute to spousal intimacy and the unavailability of adult-child care, whereas son caregivers claim their moral obligation and anticipated 
inheritance of their parents' property. These different rationales have less to do with gendered ideals than social changes that place this responsibility on males.

\section{Husband caregivers}

Intimacy-based care was frequently mentioned by husband caregivers when I asked them about their motivations. In traditional Chinese culture, spousal intimacy was viewed as a taboo that should not be shown or mentioned in public. In a country going through rapid transformation, notions of spousal intimacy have begun to take on new meanings. Most husbands in their senior years openly express their love toward their wives who are chronically ill. When I visited a 90-year-old couple in their home, Mr. Liu (\#W02) pointed to a picture in which he and his wife held hands and said, "What does it mean? Baitou xielao [Holding hands till the end of our lives]!" Unlike some caregivers who often lamented how the onset of dementia had changed their marital relationship, Mr. Liu expressed gratitude to his wife during their life-long love relationship and considered caregiving was one way that he could pay her back for past assistance. According to Liu, they had never quarreled with each other throughout their life. No matter how hard life was, they were able to find love from each other. Even though his wife suffered from dementia and could not communicate with him, Mr. Liu argued that it was the presence of his wife every day that made him very happy.

Indeed, the physical care and presence of their spouses becomes so valuable for seniors in China who are experiencing an enormous loneliness during rapid social changes (Yang et al. 2018). In Shanghai, 1.33 million families were senior-spouse-only, of which 369,500 were aged 80 and above in 2018. Among the 5.03 million elders aged 60 and above, 310,100 were living alone in 2018 (SRCA 2019). Given the unavailability of adult-child care (as I discuss below), spouses become the most reliable caregivers late in life. While acknowledging that husband caregivers have contributed a lot to taking care of their wives, they also express their need for their wives' physical presence in their daily life. For example, Mr. Huang (\#015) had taken care of his wife for almost ten years and expressed that he would not let his wife be institutionalized because "our home will no longer be a home if she is absent." The reality that there is a wife - even with dementia - waiting for you at home makes most husbands feel they are needed. Even with enormous caregiving responsibilities and limited personal time, Mr. Huang continued to spoil his wife and said, "I need her more than she needs me." Similarly, Mr. Wang (\#069) used a couple of lovers in ancient China - Liang Shanbo and Zhu Yingtai-to describe his relationship with his wife: a couple where nothing could separate them. Since his wife often got lost, Mr. Wang let her hold his arm wherever they travelled despite the hot rashes on his arm. Mr. Wang said, "Since I married her, I have to take care of her. People suggested me send her to a nursing home. I do not want to because I will miss her." The intimate marital relationship at late life stage, to some extent, has transformed the caregiving relationship into one of mutual dependence.

In addition to the intimacy of senior spouses, the unavailability of adult-child care forces senior husbands to take on caregiving. This is caused by the poor intergenerational relationship, the limited number of adult children, their children's work-care conflicts, and the nature of dementia itself. Unlike the aforementioned intimacy-based care, this group of husband caregivers often pay attention to their family situations surrounding caregiving.

Some husbands become the primary caregivers when their adult children fail to demonstrate an attitude of care towards their parents. Numerous studies on Chinese family have documented the decline in parental authority and the increase in youth power during the past four decades of reform (Shi 2017; Yan 2003). The deterioration of the practice of filial piety has been the focal point of these studies. My fieldwork findings further testify the intergenerational conflict. While the younger generation is often 
self-centered and extravagant, the older generation values intergenerational dependence and frugality. These contending values often end up with family conflicts, which force senior parents to relinquish the expectation of adult-child care. In a remarried family, Mr. Jiang (\#W05), who was taking care of his wife, complained about the reluctance of adult children to take responsibility for eldercare. Mrs. Jiang had two daughters and one son, yet none of them would take care of her after she was hospitalized. When Mr. Jiang called the three children to show up in the hospital, the senior daughter and the son were busy with their work, and the younger daughter was travelling for fun. When they showed up several days later after Mrs. Jiang was discharged, none of them were willing to engage in hands-on care. "They just hanged here and saw that their mother was not going to die soon. Then they left," said Mr. Jiang. "How can you rely on these kind of children? They barely have the sense of responsibility!"

While some adult children have the sense of filial obligation and want to contribute to caregiving, their work duties do not allow them to do so, particularly for those who are the only-child. In that situation, husbands become critical and instrumental when their wives needed care. Mr. Lu (\#093) had to take care of his wife because his only daughter and her husband had to travel each week. The lack of female caregivers forced Mr. Lu to learn cooking, housekeeping, laundry, and other skills in his 70s. These skills were important for him to maintain family function - i.e., taking care of his wife and grandson. Mr. Lu was conscientiously aware of his critical role: "I cannot be sick. If so, it would be an awkward situation since no one will be available to fill my position to take care of my wife and grandson." The Lu couple was lucky because they lived with the younger generations and maintained a good relationship with them. His daughter could help when she was not busy. Many youths in Shanghai, however, choose to live separately from their parents or work in a different city or overseas. The geographic separation of family members exacerbates the unavailability of adult-child care. The responsibility for eldercare can only be shifted to spouses.

Some other push-and-pull factors that drive husbands to become caregivers include the nature of dementia and the poor health condition of adult children. Some people with dementia do not like "strangers" - including their adult children, home aides, or service providers - to stay in their homes. Mr. Xia (\#020) was taking care of his wife in his 80s. They had three children, two in the US and one in Shanghai. Originally, Mr. Xia thought the daughter in Shanghai could provide help. He gave up this expectation because her daughter suffered from severe diabetes, obesity, hypertension, and other chronic illnesses. What made his situation more challenging was his wife did not allow "strangers" their daughter, son-in-law, and home aides - to stay at their home. Mr. Xia, even though his own health condition did not allow him to continue to caregiving, said, "I have no choice. I have to take care of her because she only knows me. Otherwise, I have to send her to a nursing home. It's too painful to do that."

\section{Son caregivers}

Although spousal caregiving is a preferred arrangement, at some point, widowed elders and senior parents who are too weak to support themselves will turn to their children for help. Among the twenty son caregivers, 17 were taking care of their widowed parents. Traditionally, adult-child care was structured by the Confucian value of filial piety. Yet, rapid social changes have transformed the meanings associated with adult-child care. Rationales of adult-child care differ remarkably: some sons prioritize their parents' needs while others negotiate their care obligation and property inheritance rights with their parents.

Sons' prioritization of their parents' needs is based on filial piety yet differs in terms of the power structure between generations. Adult sons do not necessarily show obedience or submission. Instead, 
they emphasize their moral obligation to take care of their parents. Mr. Li (\#028) was the primary caregiver for his mother. Unlike other seniors, his parents used to be the sent-down youths in Xinjiang, and his whole family stayed there for almost 30 years before returning to Shanghai. ${ }^{1}$ During this period, Mr. Li and his two siblings all grew up in Xinjiang. When they returned to Shanghai, they felt the people in Shanghai had a shallow qinqing [family affection]: they often sought economic benefits, leaving their parents unattended. On the contrary, Mr. Li remarked that his family had a deep qinqing, which made them different from local Shanghainese. Because of their family affection, $\mathrm{Mr}$. Li and his siblings never quarreled with each other. Each contributed to their mother's care based on their economic conditions. For instance, Mr. Li's sister, who was divorced and later had a car accident, had no financial contribution to their mother. His brother, who had limited education and had to continue to work to support his son for college, also contributed very little. Mr. Li did not complain about his siblings. Instead, he actively took on the primary caregiver role for their mother. While Mr. Li's economic condition allowed him to do so, he also recognized the occasional contributions from his siblings when he travelled for business: "It's our family affection that makes me feel we are human beings. Otherwise, we are no different from animals." Mr. Li's words demonstrate his strong endorsement of familism and his disappointment with the emerging individualism in Chinese society.

Indeed, parent-primacy care in contemporary China is so scarce that it makes Li so valuable. Comparing to filial piety, parent-primacy care continues to emphasize reciprocity and sacrifice within the interdependent network of kin. Yet, by comparing his own family's mutual support to those families in Shanghai who endorse individualism, Li demonstrates his moral superiority, which in turn requires him to sacrifice personal benefits for the whole family. Moreover, his strong moral obligation might be built upon the Confucian value - baishan xiao weixian, which places filial piety as the foremost goodness among hundreds of good behaviors. The lack of patriarchal relationship between Li and his mother renders his motivation into a moral orientation than simply fulfilling one's gender roles or social norms.

Contrary to the parent-primacy care, some son caregivers negotiate their eldercare responsibility with their parents and siblings. Those who turn to negotiated care believe that the allocation of care responsibility should correspond with property inheritance right. In Shanghai, the most valuable property is housing. In my previous study, I introduced a property-inheritance eldercare pattern (Zhang 2017). For adult children, their parents are sufficiently resourceful in terms of housing property, which has become an important asset worth fighting over with other family members (Davis 2010). Moreover, most elders have their own pensions, which enable them to be financially independent from their children. They also have their own bank accounts and manage their property themselves until they completely lose the ability. During my fieldwork, seniors living with their adult children chose to share daily expenses or financially support them. Given this context, the negotiated care not only highlights the continuing exchange between generations, but also indicates a transforming care norm in urban China.

With sufficient resources, both elders and adult children in Shanghai have alternative strategies to negotiate with each other on eldercare. Among the 20 son caregivers, 13 received benefits from their parents in the form of pension, savings, and housing property; five cases did not reach an agreement on the division of parents' property; and $\mathrm{Mr}$. Li and another caregiver belonged to the category of prioritizing their parents' needs. Most son caregivers, after receiving their parents' property, devoted their time and efforts to taking care of their parents. Meanwhile, they often became solo caregivers due to family disputes during the process of property division. Mr. Zha (\#054) had taken care of his mother for more than ten years. He had a brother who had immigrated to the US and a sister who lived in Shanghai. Mr. Zha became the solo caregiver because his mother gave her housing and pension to him. According to Mr. Zha, his two siblings rarely came back or contacted him since their mother made this 
decision. With enormous care responsibilities, Mr. Zha felt that he should take all care tasks because of the anticipated property. When I asked him about his solo caregiving status, he smiled and said, "Just think of myself as the only child."

Mr. Zha's family did not have obvious conflicts regarding eldercare obligation and property inheritance right. Yet, six son caregivers who were solo caregiving went through severe family conflicts to balance one's right and obligation. Regardless of family conflicts, as with Mr. Zha, these solo caregivers often end up with a broken family tie. Their engagement in eldercare was motivated by pursuing the individual right and fulfilling one's obligation rather than masculinity.

\section{Practices}

Home roles of male caregivers range from the previous tasks that require manual labor to all dimensions of care including shopping, providing transportation, managing medications, housekeeping, cooking, bathing, and toileting. Yet, husband and son caregivers respond to the increasing care needs of their elderly kin differently. Husband caregivers would take on various care tasks without the hesitation of gender roles, whereas son caregivers often think about the boundaries between "appropriate" and "inappropriate" behaviors. As men taking on caregiving, they may experience it as a discontinuity in their life. I will discuss this challenge in the next section. Here I focus on the spectrum of care tasks that men caregivers have assumed in practice. While traditional gender identity does not prevent men from taking on various care tasks, it affects sons more than husbands in their attitude toward cross-gender care practice.

The flexible gender ideology in Shanghai encourages husbands to continue their expanding home roles by taking on caregiving. As I mentioned before, after several decades of egalitarian education, men have assumed the gender equality in both institutions and domestic settings. My study found that many husbands had already engaged in domestic labor before their wives were diagnosed with dementia. Among the 40 husband caregivers, 30 had acquired pre-caregiving skills (e.g., cooking, cleaning, bathing, feeding, and toileting their children, grandchildren, or parents) before they officially took care of their wives. Thus, caregiving was a natural continuation of their previous home roles. For instance, Mr. Feng (\#067) took care of his wife who was diagnosed with early-stage dementia. When I asked whether dementia affected his wife's cooking skills, he told me that his wife rarely cooked even before her diagnosis. Mr. Feng further explained:

Don't judge me based on our appearance. I might look strong, but in reality, I do everything carefully and persistently. She looks tiny, but she often messes things up and has no patience. I do not like her ways of doing things. Since we married, I have taken most household chores, and she only takes charge of some cleaning tasks.

Because Mr. Feng played a primary role in housework, he felt it was natural to take care of his wife after her diagnosis.

The shortage of female caregivers also forces some husband caregivers to assume more home roles. Among the 40 husband caregivers, 11 had only a son or sons. Among husband caregivers who had daughters, seven had the only daughter due to the one-child policy. Meanwhile, the work-care conflicts of those who are the only child mean that their contribution to family caregiving is limited. Because of the limited female caregivers, some husbands assume all dimensions of caregiving. For example, due to the unavailability of their only son, Mr. Wang (\#069) had to take all care tasks for his wife, ranging from cooking to personal care. After five years, he felt that caregiving had become his new "job": "Every day is routinized. I treat her as my child, feeding her, guiding her to toilet, bathing her, etc. It's good to 
have something to do after retirement." The expanding home roles of husband caregivers have blurred the gender boundaries. Husband caregivers rarely complained that caregiving challenged their masculinity; rather, their nurturing activity made them feel a return to family life.

Indeed, gender roles continue to dilute at post-retirement stages of life, which makes husbands getting involved in caregiving possible. Western studies on gender roles have found that distinctions between males and females become less salient along with adult development, particularly at post-retirement stages of life (Gutmann 1980). Building upon this life-course development theory, some Western scholars further argue that husband caregivers may adjust their gender roles due to the marital contract and the necessity for sustaining the conjugal relationship (Ducharme et al. 2007; Russell 2001). This theory can also explain the increasing number of husband caregivers in China. Instead of pursuing masculinity that might be characterized by carelessness, all husband caregivers demonstrated their "feminine" nature by engaging in nurturing activities. Some husband caregivers expanded their home roles to emotional support. For example, Mr. Yu (\#057) treated his wife delicately by watching her emotions. Because his wife felt frustrated with their only daughter who was too busy to get married, Mr. Yu had to comfort her that their daughter would marry soon. "We are old now and cannot catch up social changes. As long as we are in good health, let our daughter decide her own life. Is that ok?" Mr. Yu gently talked to his wife in the memory clinic where we met.

The expanding home roles of male caregivers are also evident in son caregivers. For son caregivers who took care of their fathers, the spectrum of their care tasks is almost the same with that of husband caregivers. Yet, unlike husband caregivers who often have acquired some skills for taking care of their wives, son caregivers often encounter many challenges related to gender boundaries, particularly for those taking care of their mothers. Mr. Sun (\#W024) and his two brothers were all divorced, poor, and relied upon government subsidies. As a solo caregiver, Mr. Sun had taken care of his mother for ten years. Originally, he did not know how to take care of his mother and often messed up since his mother lost continence. Through trial and error, Mr. Sun was able to find his mother's toileting behavioral patterns and eventually figure out a daily schedule of care practice. Yet, one thing that constantly bothered him was bathing his mother. Previously, he could not overcome the psychological embarrassment and hired someone to bathe his mother. But, given his economic condition and the lack of female caregivers in his family, Mr. Sun gradually took on this personal care task.

Some son caregivers-even with the availability of their wives - have to overcome their awkward psychological reservations to bathe their mothers. This is partly due to women's withdrawal from traditional gender roles and partly due to the often-tense relationship between mothers-in-law and daughters-in-law in China (Song and Zhang 2012). Since his mother became incontinent, Mr. Tang (\#W028) had to take all care tasks for his mother, including bathing and toileting. He shared with me how to maintain a clean body for his mother:

In the morning I clean her body with a towel and in the evening, I give her a bath. I guide her to the bathroom every two hours during the day and I use diapers at night. There are no gender differences between mothers and sons. When I was a kid, my mother cleaned for me until I grew up. Now, it's my turn to take care of her.

Mr. Tang indeed received a high reputation based on what he had done for his mother. Senior neighbors often applauded his conduct toward his mother and praised him as "the most filial son" in the community. Yet, middle-aged women often gossiped his inappropriate behaviors such as bathing his mother. They even picked up a nickname for him, pa laopo, meaning "being henpecked." Mr. Tang was "henpecked" because his wife did not help him take care of his mother. Even with a wife, Mr. Tang was 
the solo caregiver for more than a decade. His two sisters became estranged after the family dispute about their mother's housing property. When I asked him about his response toward his wife, Mr. Tang explained to me:

How many daughters-in-law actually take care of their parents-in-law now? I haven't seen one! Fumei [his wife] is good enough because she allows my mother to stay with me so that I can take care of my mother and my own house issues. If she can retreat, I should also retreat and take responsibility for all care tasks so that my mother will not interrupt her.

The mutual agreement between Mr. Tang and his wife demonstrates the withdrawal of women, especially daughters-in-law, from their traditional gender roles in domestic settings. Consequently, these actions force men to assume caregiving tasks that are not always consistently with gender role expectations.

\section{Struggles and Strategies}

The expanding home roles of male caregivers does not mean they encounter zero challenges. They may experience a great deal of stress from their loss of personal autonomy, the discontinuity of their previous life, and the enormous caregiving responsibility. Working sons and husbands may also experience work-care conflicts. Despite these challenges, husband and son caregivers continue to put others' needs ahead of their own desires while seeking solutions for their own struggles. By comparing their responses, we also observe variations not based on gender but instead individual and cohort differences.

For husbands who previously did not get involved in domestic issues such as housekeeping or cooking, the initial stage of taking on caregiving means a discontinuity of their life (a quasi-"career change" that may occur after retirement). Mr. Wang (\#023) was officially retired on July 1st, 2007. He started caregiving three weeks later since his wife broke her hip and became demented. His two sons worked in the US at that time. Due to the sudden deterioration of his wife's health condition, Mr. Wang took almost all care tasks. Mr. Wang expressed his unexpected retirement life during the interview: "I thought we could travel around the world after our retirement. I never thought about being a caregiver so fast. Yet, this is our life. Since she needs me now, I'll do my best." Similarly, Mr. Huang (\#015), no matter how much he loved his wife, also expressed the loss of personal autonomy after taking on caregiving. "I have to watch her, and she also wants to be with me all the time. Now I have to give up all my hobbies," said Mr. Huang. Yet, for husband caregivers, their sense of discontinuity was easily made up by their wives' companionship and their marital contract.

Another challenge for senior husbands is the deterioration of their own health conditions along with the increasing demand of caregiving. Most husband caregivers are at the same age cohort with their wives, meaning that their own health conditions were not always good. With limited support from family members and society, many senior husband caregivers assume all of the responsibilities. Mr. Zhou (\#009) was taking care of his wife who refused to see doctors or take any medicine for treatment. Mr. Zhou could not hold his tears during the interview:

I suffer more than she does. She doesn't know my pain. I could not sleep well when I thought about her illness. My heart is not good, and I have been hospitalized twice for my heart disease. But I have to continue to take care of her because my only daughter is in America. I have to carry the pills for my heart wherever I go! 
The lack of social and family support often puts these senior husband caregivers into a moral dilemma: have I done enough for my wife, or should I send her to a nursing home for a respite? Whereas the marital contract or love has bounded senior couples to be willing to sacrifice personal autonomy for the sake of their loved ones, there is an invisible limit of their moral devotion. After several years of handson caregiving, their own health condition will not allow husband caregivers to continue to do so. The deterioration of their health conditions and/or the increasing caregiving responsibility often forces them to consider alternative strategies to take care of their wives. Some husband caregivers who are economically abundant will hire home aides for help while others will turn to their adult children for support.

Even though husband caregivers may employ outside services or turn to their adult children, their caregiving responsibilities are not over. Mr. Huang (\#015) had to sleep with his wife at night because "she wants to be with me in the same bed." Mr. Liu (\#W03) continued to take care of his wife's medication even with the assistance of a nursing aide at home. "I am worried about her drugs and the aide might mess up," said Mr. Liu. Similarly, Mr. Yu (\#W33) only outsourced care tasks that required intensive manual labor. For those who have their adult children getting involved, husband caregivers often complain about their children's lack of patience or keep an eye open on their motivation. "You have to shixiang [tell whether people like you or not]. They [adult children] have their own family issues and work duties, so you cannot always call them or bring them troubles," said Mr. Guo (\#W10). So, he only asked his daughter and son to come alternatively each week and brought them some food. Because adult-child care is often involved with inheriting parents' housing property, senior husbands must figure out how to avoid potential conflicts with their adult children when they require support. Mr. Qiao (\#W25), at the age of 90 years old, shared with me his secret to deal with his three adult children and their support:

I ask them to come over in turn. Each comes here every three days to contribute some labor...You cannot say you love this one or that one. You pretend that you like them all. Now I can still manage my finances, so I will not say who will get my house and savings. I will tell them only when I cannot move anymore.

For senior parents who are resourceful, they cannot take eldercare for granted from their adult children. They have to deliberately calculate how to balance their children's performance and the property division. Indeed, eldercare has become a battlefield between generations because it inevitably relates to the most valuable asset - parents' housing property. Even among the son caregivers, several have made a point of distinguishing the "modern" sense of care obligation based in inheritance rights from the traditional virtue of filial piety. Mr. Fan (\#030) took care of his mother who suffered from dementia. As with other adult-child caregivers, he inherited his parents' house and savings. With an increasing care demand, Mr. Fan had to quit his job to make sure his mother received more care and support. When I met him in a hospital, he told me that each day he woke up at four or five o'clock and then transported his mother to an emergency room for medical care. At that time, he had already been unemployed for nineteen days. When I praised that he was a filial son, he laughed and explained, "I have to do this to show my siblings that I take good care of my parents. Otherwise, they will gossip about you among your relatives."

Equally worth mentioning is the increasing care demand from parents affects sons who have work duties. The fact that Mr. Fan didn't seem to be worried about his work was because he received his parents' pensions - about 10,000 RMB [\$1,400 USD] each month - which was enough to support for his daily necessities. Yet, for other son caregivers who do not have such a luxury, they constantly experienced work-care conflicts. Mr. Qiu (\#008) was single and 28 years old. Yet, he had to take care of 
his mother who unfortunately suffered from dementia. Mr. Qiu had a brother who had immigrated to the US and his father passed away in 2015. When I met him in the memory clinic, Mr. Qiu was extremely depressed: he had to quit his current job to find one with flexible hours because his boss would not allow him to be absent anymore. When I learned that his mother's dementia condition might worsen, I asked Mr. Qiu whether he minded about personal care. Unlike other son caregivers who did not take gender identity as a serious issue, Mr. Qiu said it had bothered him for a long time. He did not mind cooking, cleaning, and running errands, yet he felt embarrassed to bathe and change the diaper for his mother. "I will hire a home aide to help with personal care," said Mr. Qiu. "It's not that I don't love my mother. I just cannot overcome the embarrassment."

Son caregivers who have expressed this psychological challenge are not uncommon. Among the 17 son caregivers taking care of their mothers, 9 expressed a similar attitude toward personal care. Whereas most son caregivers had taken on a broad range of caregiving tasks, personal care such as bathing or changing diapers for their mothers was interpreted as gender sensitive and left to their wives or social service providers. Moreover, compared to husband caregivers who can deal with their emotional stress by referring to their marital contract or intimacy, son caregivers often do not have a positive association with the increasing care demand from their parents. They spoke regretfully of a loss of the sociability and a sense of failure because of lack of improvement of their parents' health conditions. Some said that they had to figure out some time to read newspapers or watch TV to participate in some elements of their "normal" life, whereas others coped with this sense of loss by reinterpreting caregiving as an opportunity to repay their parents rather than focusing on issues of gender identity.

\section{Conclusion}

This paper examined the experience of the "Cinderella men" taking care of their ill family members. I argue that the effect of men as caregivers results from demographic changes, notions of intimacy, and kin responsibility more than the social construction of gender roles and power asymmetries between genders. The expanding home roles for males pose the question, "Does gender matter in caregiving?" Gender seems to matter in terms of socialization. Yet, we do not see gender as a strong influence for how caregiving is motivated and practiced. In other words, we cannot simply attribute gender as the answer to men's attitudes toward caregiving, hands-on care, service utilization, and relations with other family members. The variation should take individual and cohort differences into consideration. Instead of furthering the differences between genders, I argue that caregiving serves as a prism to reflect individual personality and moral character of caregivers, regardless of gender roles.

Variations of nurturing activities of male caregivers occur for reasons other than gender. We have observed differences between husband and son caregivers in terms of obligations and reciprocities. Husband caregivers are motived by love and affection. The unavailability of adult-child care also forces them to take the primary responsibility for their wives and cross the gender boundary by assuming a wide spectrum of caregiving tasks. In dealing with the overwhelming caregiving responsibilities, they put others' needs ahead of their own desires and forcibly adjust to the personal sacrifices. While son caregivers are also acting consistently with the expanding home roles, their motivations vary from case to case. Some prioritize their parents' needs and others are affected by the idea of inheriting property. Because of family conflicts, many son caregivers are solo caregiving, which means that they handle a broad range of caregiving tasks without the support from their siblings. In practice, there is a great variation in the tasks they perform. Some personal care tasks such as bathing and changing diapers for their mothers are considered gender sensitive for son caregivers, especially for those who are young and unmarried. In that case, these son caregivers either outsource to their wives or hire home aides. Yet, some son caregivers have overcome the psychological embarrassment after years of caregiving. 
There are cohort differences in the coping strategies by all the male caregivers that expressed their experiences with caregiving. Husband caregivers used social services or turned to their adult children for support, whereas son caregivers received support primarily from their wives or home aides; consequently, siblings-especially sisters - were absent from the caregiving process. Again, this care arrangement is due to the property inheritance. Even husband caregivers who do not need to fight over inheritance with their adult children are fully aware that if they cannot handle their property well, they will end up with poor relationship with their children. Moreover, work-care conflicts among son caregivers often create anxieties that are irrelevant for husband caregivers who have already retired. These son caregivers are more likely to report stress and burden; in addition, given the progressive nature of dementia, some son caregivers could not feel the sense of achievement in caregiving (such as the improvement of their parents' health conditions). Husband caregivers, however, view caregiving as an experience of companionship and an opportunity to repay their wives for their previous assistance; thus, they are relatively easy satisfied with their contributions.

Despite the individual and cohort differences, men who take on caregiving have a strong sense of commitment and an acceptance of their moral obligation. The fact that they must cross gender boundaries causes caregiving to transition into a gender-neutral experience. The flexible gender ideology allows these male caregivers to reshape the landscape of eldercare in China. With an increasing number of elders who need long-term care, care arrangements within domestic settings will continue to change, which may vary with economic circumstances, family relationships, and living patterns. Therefore, gender alone cannot predict the future for family caregiving. It is certain Chinese society and family will continue to change as eldercare is restructured and men are inevitably included in the process.

\section{Acknowledgments}

This research was funded by the Wenner-Gren Foundation for Anthropological Research (\#9361).

\section{Notes}

1. The sent-down youth was known as the zhiqing. They were the young people who-beginning in the 1950s until the end of the Cultural Revolution, willingly or under coercion-left the urban districts of China to live and work in rural areas for some state-led projects. After the Culture Revolution, they gradually returned to their hometown.

\section{References}

ADI (Alzheimer's Disease International). 2009 World Alzheimer Report. https://www.alz.co.uk/research/files/WorldAlzheimerReport.pdf. Accessed 06/28/2020.

Bells, Nadine. 2011. "Shanghai: Home of the World's Best Husbands." Yahoo News, March 21, https://ca.news.yahoo.com/blogs/good-news/shanghai-home-world-best-husbands-20110321-122733738.html, access 04/27/2019.

Black, H., Schwartz, A., Caruso, C., Hannum, S. 2008. "How Personal Control Mediates Suffering: Elderly Husband's Narratives of Caregiving." The Journal of Men's Studies 16 (2): 177-192.

Bureau of Labor Statistics. 2019. "Unpaid Eldercare in the US-2017-2018 Data from the American Time Use Survey." https://www.bls.gov/news.release/pdf/elcare.pdf. Accessed 06/28/2020.

Calasanti, Toni. 1999 “Feminism and Gerontology: Not Just for Women.” Hallym International Journal of Aging 1 (1): 44-55.

Chen, Xiaoru. 2012. "Why Shanghai Men Are in Demand." Global Times, March $8^{\text {th }}$. http://www.globaltimes.cn/content/699247.shtml. Accessed 04/27/2019. 
China Daily. 2006. "Shanghai Men: Henpecked or Just Polite?" July 24th http://www.chinadaily.com.cn/citylife/2006-07/24/content 647664.htm. Accessed 04/27/2019.

Da, Weiwei. 2004. “A Regional Tradition of Gender Equity: Shanghai Men in Sydney, Australia." The Journal of Men's Studies 12: 133-49.

Davis, Deborah. 2010. “Who Gets the House? Renegotiating Property Rights in Post-Socialist Urban China." Modern China 36 (5): 463-492.

Ducharme, Francine, Louise Lévesque, Lise Lachance, Marcellin Gangbè, Steven H. Zarit, Jean Vézine, and Chantal D. Caron. 2007. “Older Husbands as Caregivers: Factors Associated with Health and the Intention to End Home Caregiving." Research on Aging 29 (1): 3-31.

Engster, Daniel. 2015. Justice, Care, and the Welfare State. Oxford: Oxford University Press.

Friedemann, Marie-Luise, and Katheleen C. Buckwalter. 2014. “Family Caregiver Role and Burden Related to Gender and Family Relationships." Journal of Family Nursing 20 (3): 313-336.

Gerstel, Naomi, and Sally K. Gallagher. 2001. "Men's Caregiving: Gender and the Contingent Character of Care." Gender and Society 15 (2): 197-217.

Gutmann, David L. 1980. "Psychoanalysis and Aging: A Developmental View." In The Course of Life: Psychoanalytic Contributions Toward Understanding Personality Development: Vol.III. Adulthood and the Aging Process. Edited by Stanley I. Greenspan and George H. Pollock, 489-517. Washington, DC: National Institute of Mental Health.

Harris, Phyllis Braudy, and Susan Orpett Long. 1999. "Husbands and Sons in the United States and Japan: Cultural Expectations and Caregiving Experiences." Journal of Aging Studies 13 (3): 241-267.

Hochschild, Arlie Russell, and Anne Machung. 1989. The Second Shift: Working Parents and the Revolution at Home. New York: Viking Penguin Inc.

Jesmin, Syeda S., Iftekhar Amin, and Stanley R. Ingman. 2011. “Ageing and Caregiving Crisis in the Low and Middle Income Societies.” Indian Journal of Gerontology 25 (3): 309-328.

Jin, Yihong. 2006 “Rethinking the 'Iron Girls': Gender and Labor during the Chinese Cultural Revolution." Gender and History 18 (3): 613-634.

Li, Yuhui. 2000. “Women's Movement and Change of Women's Status in China." Journal of International Women's Studies 1 (1): 30-40.

Long, Susan Orpett, and Phyllis Braudy Harris. 2000. "Gender and Eldercare: Social Change and the Role of the Caregivers in Japan." Social Science Japan Journal 3 (1): 21-36.

Long, Yingtai. 1999. Ah, Shanghai Men. Shanghai, China: Xuelin Press.

Miller, Baila, and Julie E. Kaufman. 1996. “Beyond Gender Stereotypes: Spouse Caregivers of Persons with Dementia." Journal of Aging Studies 10 (3): 189-204.

Montgomery, Rhonda J.V. 1992. "Gender Differences in Patterns of Child-Parent Caregiving Relationships.” In Gender, Families, and Elder Care. Edited by Jeffrey Dwyer, and Raymond Coward, 65-83. Newbury Park, CA: Sage.

Neufeld, Anne, and Kaysi Eastlick Kushner. 2009. “Men Family Caregivers' Experience of Non-Supportive Interactions: Context and Expectations." Journal of Family Nursing 15 (2): 171-197.

Robinson, Fiona. 2011. The Ethics of Care: A Feminist Approach to Human Security. Philadelphia: Temple University Press.

Russell, Richard. 2001. "In Sickness and in Health: A Qualitative Study of Elderly Men Who Care for Wives with Dementia." Journal of Aging Studies 15: 351-367.

Russell, Richard. 2007. “The Work of Elderly Men Caregivers: From Public Careers to an Unseen World.” Man and Masculinity 9 (3): 298-314. 
Sharma, Nidhi, with Subho Chakrabarti, and Sandeep Grover. 2016. "Gender Differences in Caregiving among Family Caregivers of People with Mental Illness." World Journal of Psychiatry 6 (1): 7-17.

Shi, Lihong. 2017. Choosing Daughters: Family Change in Rural China. Stanford, CA: Stanford University Press.

Song, Yi, and Yan Bing Zhang. 2012. "Husbands' Conflict Styles in Chinese Mother/Daughter-in-Law Conflicts: Daughters-in-Law's Perspectives." Journal of Family Communication 12 (1): 54-74.

SRCA (Shanghai Research Center on Aging). 2019. "Report of the Statistics of Older Population and Social Services Development in 2018." http://www.shrca.org.cn/News/detail.aspx?ID=6892\&Page=0, accessed 03/10/2020.

Swinkels, Joukje, Theo van Tilburg, Ellen Verbakel, and Marjolein Broese van Groenou. 2019. Explaining the Gender Gap in the Caregiving Burden of Partner Caregivers. The Journals of Gerontology: Series B 74 (2): 309-317.

Tao, Jie, with Zheng Bijun, and Shirley L. Mow, eds. 2004. Holding up Half the Sky: Chinese Women Past, Present, and Future. New York: The Feminist Press.

Traphagan, John. 2003. “Older Women as Caregivers and Ancestral Protection in Rural Japan.” Ethnology 42 (2): 127-139.

Tronto, Joan. 1993. Moral Boundaries: A Political Argument for an Ethics of Care. New York: Routledge.

Tsai, Kellee. 1996. “Women and the State in Post-1949 Rural China.” Journal of International Affairs 49 (2): $493-524$.

Vogel, Suzanne. 1978. "Professional Housewife: The Career of Urban Middle Class Japanese Women." Japan Interpreter 12: 16-43.

Xie, Yu. 2013. Gender and Family in Contemporary China. University of Michigan: Population Studies Center Research Reports 13-808.

Xu, Qiong, and Wei-jun Jean Yeung. 2013. “Hoping for a Phoenix: Shanghai Fathers and Their Daughters." Journal of Family Issues 34: 182-207.

Yan, Yunxiang. 2003. Private Life under Socialism: Love, Intimacy, and Family Change in a Chinese Village (1949-1999). Stanford: Stanford University Press.

Yang, Fang, with Zhang Junan, and Wang Jianping. 2018. "Correlates of Loneliness in Older Adults in Shanghai, China: Does Age Matter?" BMC Geriatrics 18: 300. doi:10.1186/s12877-018-0994-x

Yee, Jennifer L., and Richard Schulz. 2000. “Gender Differences in Psychiatric Morbidity among Family Caregivers: A Review and Analysis." The Gerontological Society of America 40 (2): 147-164.

Yin, Zhigang, and Zhou Haiwang. 2014. Shanghai Shi Laonian Renkou Zhuangkuang yu Yiyuan Fazhan Baogao (19982013) [The Demographic Status and Attitudes toward Eldercare Report in Shanghai (1998-2013)]. Shanghai: Shanghai Academy of Social Sciences Press.

Zhang, Hong, and Elizabeth Fussell. 2017. "Strategic Gender Egalitarianism in Rural China: The Impacts of Husbands' Migration on Gender Relations." American Behavioral Scientist 61 (10): 1192-1213.

Zhang, Yan. 2017. "Contextualized Eldercare in the Post-Reform Era of China: Cultural Categories of Elder Mistreatment and the Potential Social Causes." Ageing International 42 (2): 169-186. 